\title{
Filamentous fungi diversity in the natural fermentation of Amazonian cocoa beans and the microbial enzyme activities
}

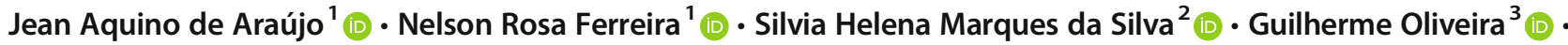 Ruan Campos Monteiro ${ }^{4}$ (D) Yamila Fernandes Mota Alves ${ }^{1}$ (D) - Alessandra Santos Lopes ${ }^{1}$ (D)}

Received: 18 September 2018 / Revised: 13 May 2019 / Accepted: 29 May 2019 / Published online: 20 June 2019

(C) Università degli studi di Milano 2019

\begin{abstract}
Purpose The purpose of this study was to investigate the diversity of filamentous fungi and the hydrolytic potential of their enzymes for a future understanding of the influence of these factors on the sensory characteristics of the cocoa beans used to obtain chocolate.

Methods Filamentous fungi were isolated from the natural cocoa fermentation boxes in the municipality of Tucuman, Pará, Brazil, and evaluated for the potential production of amylases, cellulases, pectinases, and xylanases. The fermentation was monitored by analyzing the $\mathrm{pH}$ and temperature. The strains were identified by sequencing the ITS1/ITS 4 section of the 5.8S rDNA and partially sequencing the $18 \mathrm{~S}$ and $28 \mathrm{~S}$ regions, and the molecular identification was confirmed by phylogenetic reconstruction.

Result The fungi isolated were comprised of three classes from the Ascomycota phylum and one class from the Basidiomycota phylum. There were found 19 different species, of this amount 16 had never been previously reported in cocoa fermentation. This fact characterizes the fermentation occurring in this municipality as having wide fungal diversity. Most of the strains isolated had the ability to secrete enzymes of interest. Cladosporium cladosporioides, Fomitopsis subtropical, Aspergillus versicolor, Penicillium pimiteouiense, Phanerochaete australis, Neonothopanus nambi, and Aspergillus parasiticus were the strains that excelled in the secretion of the following enzymes: amylase, pectinase, cellulase, and xylanase.

Conclusion The presence of 16 species not yet reported in cocoa seed fermentations and their potential hydrolytic activities show a diversity of filamentous fungi in this microbial biome that needs to be better understood.
\end{abstract}

Keywords Amylase $\cdot$ Cellulase $\cdot$ Filamentous fungi $\cdot$ Pectinase $\cdot$ Theobroma cocoa $\cdot$ Xylanase

Nelson Rosa Ferreira

nelson.ufpa@gmail.com

Alessandra Santos Lopes

alessalopes@ufpa.br

1 Laboratory of Biotechnological Processes. Program of Post-Graduation in Food Science and Technology (PPGCTA), Federal University of Pará (UFPA), Belém, Pará 66075-110, Brazil

2 Mycology Laboratory, Section of Bacteriology and Mycology, Evandro Chagas Institute (IEC/SVS/MS), BR 316, km 7, Ananindeua, Pará 67.030-000, Brazil

3 Instituto Tecnológico Vale (ITV), Belém, Pará 66.055-090, Brazil

4 Graduate Program of Biology of Infectious Agents and Parasitological, Institute of Biological Sciences, Federal University of Pará (UFPA), Belém, Pará 66075-110, Brazil

\section{Introduction}

Fermentation is one of the steps in cocoa processing. It occurs spontaneously and starts soon after harvesting and breaking of the fruits, which is carried out by the cocoa cultivators to develop the characteristic chocolate flavor (Nielsen et al. 2007). In this step, the overlay of the seed pulp is degraded by the action of microorganisms (fungi and bacteria) and this process causes an elevation in temperature which can reach values near $50^{\circ} \mathrm{C}$ (Abdullahi et al. 2018).

The microorganisms present in the cocoa fermentation process hydrolyze the sugars and organic acids of the pulp into simple sugars, which are processed into ethanol, lactic acid, and acetic acid (Schwan and Wheals, 2004). The acids generated penetrate the seeds, and together with the increase in temperature, cause the death of the embryo, a desirable action in the cocoa fermentation process (Macedo et al. 2013). 
Of the microorganisms present in the fermentation of cocoa, the filamentous fungi are highly important, since they grow abundantly in habitats where polymeric compounds are present, such as those found in the cocoa pulp (pectin, starch, and cellulose). The fungi possess advantages over other microorganisms due to their ability to assimilate a variety of substrates to produce enzymes (Chan et al. 2018).

The filamentous fungi are found during all the primary stages of cocoa bean processing (fermentation, drying, and storage), but their activity during cocoa fermentation is not yet fully known (Copetti et al. 2011a). It is therefore of utmost importance to identify and characterize the compounds generated by the strains, especially the enzymes that act during cocoa fermentation.

A study carried out in Cameroon reported the occurrence of filamentous fungi during the cocoa fermentation process and identified Aspergillus and Penicillium species (Mounjouenpou et al. 2012). A study carried out in Brazil on the presence of filamentous fungi during cocoa fermentation identified the species Absidia corymbifera, Aspergillus candidus, A. carbonarius, A. flavus, A. fumigatus, A. niger, A. parasiticus, A. sydowii, A. versicolor, Eurotium amstelodami, Geotrichum candidum, Monascus ruber, Mucor sp., Paecilomyces variotii, Penicillium paneum, Rhizopus, and Syncephalastrum sp. (Copetti et al. 2011a).

The production of extracellular enzymes by filamentous fungi is diverse, but some are more technologically relevant, such as amylase, cellulase, xylanase, and the pectinases, since these are used to hydrolyze complex polysaccharides into simple sugars. These enzymes are useful in food processing, breweries, and the biofuel industries (Reddy and Sreeramulu 2012). It is therefore important to search for new sources of extracellular enzymes in their natural habitats, which have not yet been reported and which might constitute a real technological potential with desirable characteristics (high activity, high temperature stability, and wide $\mathrm{pH}$ ranges) (Damaso et al. 2012).

Different methods can be used to select microorganisms by determining the presence of extracellular enzymes. These methods include the use of solid culture medium containing substrate inductors which allow for visualization of the hydrolysis reaction (Larone, 2002). This technique is based on the use of a solid medium consisting of agar, mineral salts, and the substrate inductor (a single carbon source available in the environment), and coloring agents that visualize the hydrolysis reaction. These coloring agents bind to systems between the polymeric molecule structures, such that when the molecules are hydrolyzed, a halo of hydrolysis is formed.

Taxonomic classification methodologies by way of molecular biology are increasingly common and necessary as against classical taxonomy, since they use specific molecular markers, which, in the case of fungi, is the 18S rDNA gene (ribosomal DNA) (Cocolin and Ercolini, 2008; Watanabe, 2010). These methodologies incorporate various techniques required for the identification of microorganisms, such as DNA extraction, the polymerase chain reaction (PCR), agarose gel electrophoresis, and genetic sequencing (Justé et al. 2008; Godet and Munaut 2010).

It is important to note that the filamentous fungi are present during the cocoa fermentation stage regardless of the geographic location and are potential producers of extracellular enzymes of biotechnological interest, but detailed work on this class of microorganisms during cocoa fermentation has not yet been carried out. Thus, the present study aimed to identify the species involved in the fermentation of cocoa in the State of Pará, Brazil, and evaluate their potential to produce hydrolytic enzymes of interest both in cocoa fermentation and for other biotechnological applications.

\section{Material and methods}

\section{Cocoa seed collection}

The cocoa seeds were collected in the first week of July in Tucuman, a municipality in the Brazilian Amazon, located in the southern region of the State of Pará (latitude: 06 51' 44"S and longitude: $51^{\circ} 09^{\prime} 40^{\prime \prime} \mathrm{W}$ ). The seeds were maintained in three wooden trough fermenters (A1, A2, and A3), each containing approximately $500 \mathrm{~kg}$ of seeds, and were covered by banana leaves for 7 days of natural fermentation under the conditions laid down by local cocoa farmers. Samples were taken at zero time and at 24-h intervals from different points in the trough fermenters, for analysis $(\mathrm{pH})$ and the isolation of microorganisms. Samples (200 g per day for 8 sampling periods) were taken from seeds located at the surface, in the middle, and at the bottom of the troughs, giving a total weight of $4.8 \mathrm{~kg}$. The samples were placed in polyethylene bags, but one part $(50 \%)$ of each sample was immediately placed at $18{ }^{\circ} \mathrm{C}$ and subsequently maintained at this temperature, while the other part was stored at a temperature of $4{ }^{\circ} \mathrm{C}$ for the microbiological analyses.

\section{Monitoring of the fermentation process}

The temperatures and $\mathrm{pH}$ values were determined after 0,24 , $48,72,96,120,144$, and $168 \mathrm{~h}$ of fermentation. The temperature was measured in situ by immersing the electrode directly into the pulp at random points on the surface, middle, and bottom of the fermenter troughs using a digital thermometer (Instruthemp ${ }^{\circledR}$, Mod. HT-600).

The hydrogen potential $(\mathrm{pH})$ was measured in the laboratory using a digital $\mathrm{pH}$ meter $\left(\mathrm{Bel}{ }^{\circledR}\right.$, Mod. W3B) verifying the $\mathrm{pH}$ of samples corresponding to the same fermentation periods cited above according to the AOAC 970.21 method (APHA 2001). All samples were analyzed in triplicate. 


\section{Isolation of filamentous fungi}

The seeds $(25 \mathrm{~g})$ were pounded and mixed with $1 \%$ of BPW (Acumedia ${ }^{\circledR}$, Indaiatuba/SP, BR) $(225 \mathrm{~mL})$, and decimal dilutions $\left(10^{-1}\right.$ to $\left.10^{-7}\right)$ prepared using the same diluent. Each dilution was surface plated by streaking on Potato Dextrose Agar medium-PDA (Fluka ®, São Paulo, SP, BR) supplemented with $100 \mathrm{mg} \mathrm{L}^{-1}$ chloramphenicol (Sigma ${ }^{\circledR}$, São Paulo, SP, BR). The plates were incubated at $30{ }^{\circ} \mathrm{C}$ for 7 days (Najafzadeh et al. 2010). For the sampling procedure, dilutions with growth between 15 and 150 colonies were considered. The strains of filamentous fungi were differentiated and isolated through the macro (was studied on the basis of diameter, elevation, margins, texture of the colony as well as color of the colony from the top and reverse of the plate) and micromorphological characteristics of the vegetative and reproductive structures (all isolates were examined using oil immersion with a microscope with up to $\times 100$ magnification).

\section{DNA isolation and sequencing}

The methodology described by Chen et al. (2001) with adjustments was used to obtain the fungal biomass. Each filamentous fungal isolate was inoculated into a plastic tube containing $5 \mathrm{~mL}$ of Czapek's liquid (Sigma ${ }^{\circledR}$, São Paulo, SP, BR) with the addition of $10 \%$ yeast extract (Sigma ${ }^{\circledR}$, São Paulo, SP, BR), and incubated at $30^{\circ} \mathrm{C}$ for a further 10 days.

The internal transcribed spacer (ITS) region amplification reaction was applied following the methodology described by Khokhar et al. (2011). The oligonucleotide primers ITS1 (5'TCCGTAGGTGAACCTGCGG-3') and ITS4 (5'-TCCT CCGCTTATTGATATGC-3') were used for a total amplification of the ITS region. The PCR reactions were carried out in a thermal cycler (Hybaid, Thermo PX2 RU) as follows: initial denaturation at $95^{\circ} \mathrm{C}$ for $5 \mathrm{~min}$, followed by 35 cycles at $94{ }^{\circ} \mathrm{C}$ for $1 \mathrm{~min}$ (denaturing), $55.5^{\circ} \mathrm{C}$ for $2 \mathrm{~min}$ (ringing), $72{ }^{\circ} \mathrm{C}$ for $2 \mathrm{~min}$ (extension), and the final extension at $72{ }^{\circ} \mathrm{C}$ for $10 \mathrm{~min}$.

Purification of the PCR products was accomplished using a commercial HiYield Gel/PCR DNA mini kit (Real Biotech Corporation, China) following the manufacturer's recommendations. Sequencing was carried on by the Sanger Method using the BigDye kit. REF and read in a ABI3730 sequencer (Applied Biosystems ${ }^{\circledR}$, Mod. 3730, Carlsbad, CA, USA). The same primers $(0.5 \mathrm{pmol})$ used in the PCR (ITS1 and ITS4) for the sequencing reaction of the ITS region were employed in this procedure.

\section{Sequence analysis and phylogenetic reconstruction}

The annotation of the sequences obtained was carried out using the Geneious ${ }^{\circledR}$ (version 9.1.5) program, and they were then compared to the GenBank database using BLAST (Basic Local Alignment Search Tool). Thus, the percentage of similarity of the sequences corresponding to the ITS region of the fungi isolated in this study was obtained in relation to sequences already deposited in the Genbank. A sequence with ident $>98 \%$ was considered to identify the species of filamentous fungi.

Sequences from GenBank were downloaded for confirmation of the molecular identification by phylogenetic reconstruction. After an initial identification based on comparison with the GenBank, a set of each cluster was assembled. The set was submitted to a model test to fit the best model nucleotide substitution. Phylogenetic reconstruction was carried out by the maximum likelihood (ML) method with 1000 bootstrap replicates (bt) (Felsenstein 1985) using MEGA 7 (Kumar et al. 2016).

\section{The enzymatic potential of filamentous fungi}

Fragments of mycelium produced on the PDA medium in the Petri dishes were inoculated into the mineral salt medium with the specific carbon sources for each enzyme. All cultures were incubated at $30^{\circ} \mathrm{C}$ for $72 \mathrm{~h}$. After the incubation period, any degradation halos were visualized with Lugol's iodine solution (for amylases, pectinases and xylanase) and Congo Red solution (for cellulase). The tests were carried out in duplicate.

\section{Amylolytic potential}

The methodology of Deb et al. (2013) was used with adjustments. The mineral salt agar medium was prepared with $\mathrm{MgSO}_{4} \cdot 7 \mathrm{H}_{2} \mathrm{O}\left(0.5 \mathrm{~g} \mathrm{~L}^{-1}\right), \mathrm{NaNO}_{3}\left(1.0 \mathrm{~g} \mathrm{~L}^{-1}\right), \mathrm{KH}_{2} \mathrm{PO}_{4}$ $\left(1.0 \mathrm{~g} \mathrm{~L}^{-1}\right), \mathrm{Fe}_{2} \mathrm{SO}_{4}\left(0.01 \mathrm{~g} \mathrm{~L}^{-1}\right)$, and agar $\left(20 \mathrm{~g} \mathrm{~L}^{-1}\right)$ with soluble starch $\left(20.0 \mathrm{~g} \mathrm{~L}^{-1}\right)$ as the single carbon source. In order to reveal halo formation, $15 \mathrm{~mL}$ of Lugol's iodine solution was poured onto the surface of the plates and discarded shortly after, and the plates incubated at $30{ }^{\circ} \mathrm{C}$ for $10 \mathrm{~min}$. Amylolytic activity was detected by a light halo surrounded by a blue zone (Teather and Wood 1982).

\section{Pectinolytic potential}

The mineral salt agar medium was prepared with $\mathrm{NaNO}_{3}$ $\left(2.0 \mathrm{~g} \mathrm{~L}^{-1}\right), \mathrm{KH}_{2} \mathrm{PO}_{4}\left(1.0 \mathrm{~g} \mathrm{~L}^{-1}\right), \mathrm{MgSO}_{4} \cdot 7 \mathrm{H}_{2} \mathrm{O}\left(0.5 \mathrm{~g} \mathrm{~L}^{-1}\right)$, $\mathrm{KCl}\left(0.5 \mathrm{~g} \mathrm{~L}^{-1}\right), \mathrm{Fe}_{2} \mathrm{SO}_{4}\left(0.01 \mathrm{~g} \mathrm{~L}^{-1}\right)$, agar $\left(20.0 \mathrm{~g} \mathrm{~L}^{-1}\right)$, and citrus pectin $\left(10.0 \mathrm{~g} \mathrm{~L}^{-1}\right)$ using the methodology adapted from Damaso et al. (2012). The halo of pectin degradation was observed by adding $15 \mathrm{~mL}$ Lugol's iodine solution with subsequent disposal of the excess. The formation of clear or yellowish areas around the colonies demonstrated the presence of pectinolytic activity.

\section{Cellulolytic potential}

This was evaluated according to the methodology of AlvarezNavarrete et al. (2015) with modifications. The mineral salt agar medium was prepared with $2.0 \mathrm{~g} \mathrm{~L}^{-1}$ of $\mathrm{NaNO}_{3}$, 
$1.0 \mathrm{~g} \mathrm{~L}^{-1}$ of $\mathrm{KH}_{2} \mathrm{PO}_{4}, 0.5 \mathrm{~g} \mathrm{~L}^{-1}$ of $\mathrm{MgSO}_{4} \cdot 7 \mathrm{H}_{2} \mathrm{O}, 0.5 \mathrm{~g} \mathrm{~L}^{-1}$ of $\mathrm{KCl}, 0.01 \mathrm{~g} \mathrm{~L}^{-1}$ of $\mathrm{Fe}_{2} \mathrm{SO}_{4}$, and $15.0 \mathrm{~g} \mathrm{~L}^{-1}$ of agar, with the addition of $10.0 \mathrm{~g} \mathrm{~L}^{-1}$ of CMC as the single carbon source. To visualize any halos, $15 \mathrm{~mL}$ of $0.1 \%$ Congo Red solution was poured onto the surface of the plates. After $30 \mathrm{~min}$, this solution was discarded and $15 \mathrm{~mL}$ of $1 \mathrm{~N} \mathrm{NaOH}$ solution was added. After $10 \mathrm{~min}$, the $\mathrm{NaOH}$ solution was discarded and any cellulolytic activity revealed by the formation of clear or yellowish/reddish halos around the colonies.

\section{Xylanolytic potential}

This was evaluated according to the methodology described by Hankin and Anagnostakis (1975) with modifications. A medium composed of $2.5 \mathrm{~g} \mathrm{~L}^{-1}$ peptone, $2.5 \mathrm{~g} \mathrm{~L}^{-1}$ of yeast extract, and $1.0 \mathrm{~g} \mathrm{~L}^{-1}$ of xylan as the single carbon source was used. Any halo formation was revealed by adding, with subsequent disposal, $15 \mathrm{~mL}$ Lugol's iodine solution to the plates, where the immediate formation of yellow or orange halos around the colonies showed the production of xylanase by the filamentous fungus.

\section{Determination of the El}

This was calculated from the ratio between the mean diameter of the degradation halo and the average diameter of the colony of the filamentous fungus. Any isolated fungi that showed an enzymatic index (EI) of 2 or more was considered to be a good producer of that extracellular enzyme (Dias et al. 2005).

\section{GRI}

This was obtained from the ratio between the final size of the colony and the incubation time $(72 \mathrm{~h})$. The results obtained were expressed in millimeters per hour $\left(\mathrm{mm} \mathrm{h}^{-1}\right)$ (Visintin et al. 2016).

\section{Statistical analysis}

The statistical analyses were carried out using the Statistica ${ }^{\circledR}$ software, version 10.0, carrying out a randomized design to obtain the results. The differences between the averages were evaluated by Tukey's multiple comparison test $(p<0.05)$.

\section{Results}

\section{Monitoring the fermentation of the cocoa beans and isolation of the fungi}

The average values for the temperature during fermentation showed differences from that at zero time. The highest temperatures were observed after 48 and $72 \mathrm{~h}$ (Fig. 1).

The highest $\mathrm{pH}$ value was observed at zero time, differing from the values obtained at the other fermentation times. The average $\mathrm{pH}$ value decreased during the first $96 \mathrm{~h}$ of fermentation of the cocoa beans.

A total of 19 strains of filamentous fungi were isolated with different gross morphological features. The greatest diversity of isolated fungi $(n=7)$ was found up to $24 \mathrm{~h}$ of fermentation (Fig. 1).

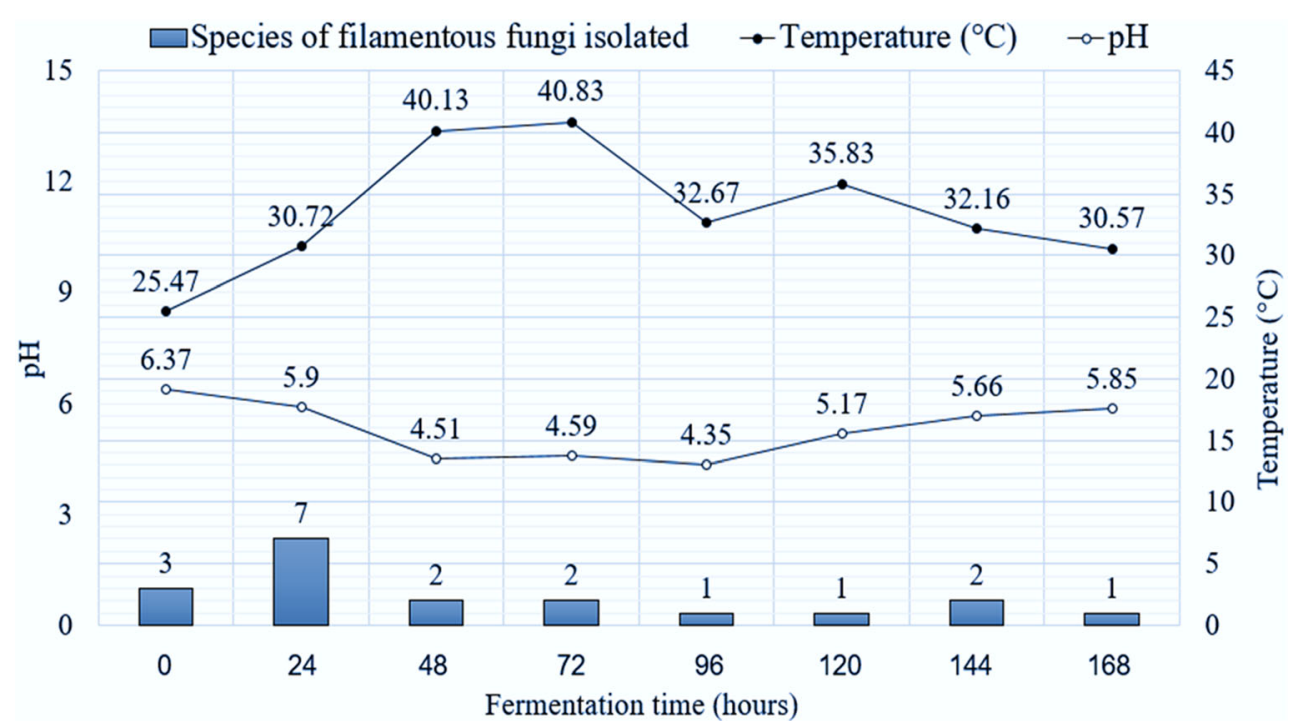

Fig. 1 Means of temperature, $\mathrm{pH}$, and filamentous fungi isolated during the cocoa bean fermentation: $0 \mathrm{~h}$ (Perenniporia tephropora, Neonothopanus nambi, and Aspergillus parasiticus), $24 \mathrm{~h}$ (Cladosporium cladosporioides, Aspergillus versicolor, Diaporthe pseudomangiferae, Diaporthe phaseolorum, Diaporthe tectonae,
Marasmius cladophyllus, and Diaporthe lithocarpus), $72 \mathrm{~h}$ (Penicilliun rubidurum and Penicillium pimiteouiense), $96 \mathrm{~h}$ (Penicillium pimiteouiense), $120 \mathrm{~h}$ (Phyllosticta capitalensis), $144 \mathrm{~h}$ (Daldinia eschscholtzii and Fomitopsis subtropica), and $168 \mathrm{~h}$ (Penicillium paneum) 


\section{Molecular identification and enzymatic potential}

The amplification of the ITS region allowed for the identification of 19 species of filamentous fungi (Table 1).

In order to be considered a potential producer of a given extracellular enzyme, a filamentous fungus must have an EI equal to or greater than 2 (Bouras et al. 2009). In the amylase test, only the fungi Aspergillus versicolor (FF05) and A. parasiticus (FF16) were considered as potential amylase producers (Table 1), although $84 \%$ of the lines showed positive results for amylase production.

The fungi C. cladosporioides (FF01), F. subtropical (FF03), A. versicolor (FF05), and P. pimiteouiense (FF10) presented the highest enzymatic levels for cellulase production (Table 1). Of the filamentous fungi isolated, $68 \%$ presented EI values between 1.0 and 1.7 (Table 1), not being considered good cellulase producers by the methodology adopted. The fungi C. cladosporioides (FF01), A. versicolor (FF05), and $N$. nambi (FF14) showed EI values greater than 2 for xylanase and were therefore considered as potential xylanase producers.

\section{GRI}

Another test carried out to determine the enzymatic potential of the filamentous fungi isolated was the growth rate index (GRI)
(Fig. 2). It was observed that fungi of the genera Talaromyces, Fomitopsis, Penicillium, Aspergillus, Daldinia, Neonothopanus, Phyllosticta, and Cladosporium presented GRI values below $0.35 \mathrm{~mm} / \mathrm{h}$ for all the carbon sources tested. Fungi of the genus Diaporthe presented a GRI value of $<$ $0.35 \mathrm{~mm} / \mathrm{h}$ when carboxymethylcellulose was used as the carbon source and reasonable growth $(0.35$ to $0.82 \mathrm{~mm} / \mathrm{h})$ when xylan was used as the carbon source.

The fungus Phanerochaete australis (FF11) stood out among the other fungi isolated, presenting high GRI values $(>1.00 \mathrm{~mm} /$ h) in two of the carbon sources tested (pectin and xylan).

In general, seven of the fungi isolated (FF01, FF03, FF05, FF10, FF11, FF14, and FF16) showed enzymatic potential in some of the tests carried out. The isolate FF01 (Cladosporium cladosporioides) showed good EI values for pectinolytic, cellulolytic, and xylanolytic activities.

\section{Phylogenetic reconstruction}

The fungi isolated comprised three classes from the Ascomycota phylum and one class from the Basidiomycota phylum after the initial Blast identification. These clusters were classified as follows: (1) phylum Ascomycota, class Eurotiomycetes; (2) phylum Ascomycota, class Sordariomycetes; (3) phylum Ascomycota,

Table 1 Molecular identification and enzymatic potential of filamentous fungi isolated in cocoa fermentation

\begin{tabular}{|c|c|c|c|c|c|c|}
\hline \multirow[t]{2}{*}{ Code name/GenBank ID accession no. } & \multirow[t]{2}{*}{ Genera/specie } & \multirow[t]{2}{*}{ Closely related species } & \multicolumn{4}{|c|}{ Enzymatic index (EI) } \\
\hline & & & Amylase & Pectinase & Cellulase & Xylanase \\
\hline FF01/MF039221 & Cladosporium cladosporioides & HM148014 & $1.2 \mathrm{e} \pm 0.0$ & $2.1 \mathrm{ab} \pm 0.1$ & $4.0 \mathrm{a} \pm 0.0$ & $\mathbf{2 . 5 a} \pm \mathbf{0 . 0}$ \\
\hline FF02/MF039205 & Talaromyces macrosporus & KU204425 & $1.1 \mathrm{f} \pm 0.1$ & $0.9 \mathrm{f} \pm 0.0$ & $1.7 \mathrm{e} \pm 0.0$ & $1.0 \mathrm{~h} \pm 0.0$ \\
\hline FF03/MF039206 & Fomitopsis subtropica & KR605787 & $1.0 \mathrm{fg} \pm 0.0$ & $2.0 \mathrm{ab} \pm 0.0$ & $3.0 \mathrm{c} \pm \mathbf{0 . 0}$ & $1.6 \mathrm{~d} \pm 0.0$ \\
\hline FF04/MF039207 & Penicillium paneum & AB479311 & $0.0 \mathrm{k} \pm 0.0$ & $0.0 \mathrm{~g} \pm 0.0$ & $0.0 \mathrm{j} \pm 0.0$ & $1.1 \mathrm{~g} \pm 0.0$ \\
\hline FF05/MF039208 & Aspergillus versicolor & FJ878627 & $2.1 b \pm 0.2$ & $1.9 \mathrm{~b} \pm 0.1$ & $3.7 \mathbf{b} \pm \mathbf{0 . 0}$ & $2.6 \mathrm{a} \pm \mathbf{0 . 0}$ \\
\hline FF06/MF039209 & Penicilliun rubidurum & KP942950 & $1.0 \mathrm{fg} \pm 0.0$ & $1.1 \mathrm{ef} \pm 0.0$ & $1.6 \mathrm{ef} \pm 0.1$ & $1.2 \mathrm{fg} \pm 0.0$ \\
\hline FF07/MF039210 & Talaromyces radicus & MH862702 & $1.5 \mathrm{~d} \pm 0.1$ & $1.1 \mathrm{ef} \pm 0.2$ & $1.5 \mathrm{f} \pm 0.0$ & $1.2 \mathrm{fg} \pm 0.1$ \\
\hline FF08/MF039211 & Daldinia eschscholtzii & KT936499 & $1.0 \mathrm{fg} \pm 0.0$ & $1.0 \mathrm{ef} \pm 0.0$ & $1.5 \mathrm{f} \pm 0.0$ & $1.6 \mathrm{~d} \pm 0.0$ \\
\hline FF09/MF039212 & Diaporthe pseudomangiferae & KT972131 & $0.9 \mathrm{~g} \pm 0.0$ & $0.0 \mathrm{~g} \pm 0.0$ & $1.2 \mathrm{gh} \pm 0.0$ & $0.9 \mathrm{hi} \pm 0.0$ \\
\hline FF10/MF039213 & Penicillium pimiteouiense & HQ646589 & $1.8 \mathrm{c} \pm 0.0$ & $1.4 \mathrm{c} \pm 0.1$ & $2.1 \mathrm{~d} \pm \mathbf{0 . 0}$ & $1.1 \mathrm{~g} \pm 0.1$ \\
\hline FF11/MF039214 & Phanerochaete australis & KP135078 & $0.0 \mathrm{k} \pm 0.0$ & $1.0 \mathrm{ef} \pm 0.0$ & $0.0 \mathrm{j} \pm 0.0$ & $1.0 \mathrm{~h} \pm 0.0$ \\
\hline FF12/MF039222 & Diaporthe phaseolorum & KX020564 & $0.6 \mathrm{~h} \pm 0.1$ & $0.0 \mathrm{~g} \pm 0.0$ & $1.2 \mathrm{gh} \pm 0.0$ & $0.8 \mathrm{i} \pm 0.0$ \\
\hline FF13/MF039215 & Perenniporia tephropora & HQ848472 & $0.5 \mathrm{i} \pm 0.0$ & $1.0 \mathrm{ef} \pm 0.0$ & $0.0 \mathrm{j} \pm 0.0$ & $1.1 \mathrm{~g} \pm 0.0$ \\
\hline FF14/MF039216 & Neonothopanus nambi & KJ206982 & $1.0 \mathrm{fg} \pm 0.0$ & $1.4 \mathrm{c} \pm 0.0$ & $1.3 \mathrm{~g} \pm 0.1$ & $2.1 b \pm 0.1$ \\
\hline FF15/MF039223 & Diaporthe tectonae & KU712437 & $0.2 \mathrm{j} \pm 0.0$ & $1.1 \mathrm{ef} \pm 0.0$ & $1.3 \mathrm{~g} \pm 0.1$ & $0.9 \mathrm{hi} \pm 0.0$ \\
\hline FF16/MF039217 & Aspergillus parasiticus & KJ175436 & $2.3 \mathbf{a} \pm \mathbf{0 . 0}$ & $1.2 \mathrm{e} \pm 0.0$ & $1.5 \mathrm{f} \pm 0.0$ & $1.2 \mathrm{fg} \pm 0.0$ \\
\hline FF17/MF039218 & Marasmius cladophyllus & KF241549 & $0.0 \mathrm{k} \pm 0.0$ & $0.9 \mathrm{f} \pm 0.0$ & $1.0 \mathrm{i} \pm 0.0$ & $1.1 \mathrm{~g} \pm 0.0$ \\
\hline FF18/MF039224 & Diaporthe lithocarpus & KR703276 & $0.4 \mathrm{ij} \pm 0.0$ & $0.0 \mathrm{~g} \pm 0.0$ & $1.0 \mathrm{i} \pm 0.1$ & $0.8 \mathrm{i} \pm 0.0$ \\
\hline FF19/MF039220 & Phyllosticta capitalensis & KU204425 & $0.0 \mathrm{k} \pm 0.0$ & $1.0 \mathrm{ef} \pm 0.0$ & $1.7 \mathrm{e} \pm 0.0$ & $1.8 \mathrm{c} \pm 0.0$ \\
\hline
\end{tabular}

*Values represent the mean of three repetitions \pm standard deviation. Means followed by the same letter in the same column do not differ statistically by Tukey test at $5 \%$ significance. The values in bold represent the enzymatic index (IE) greater than 2 


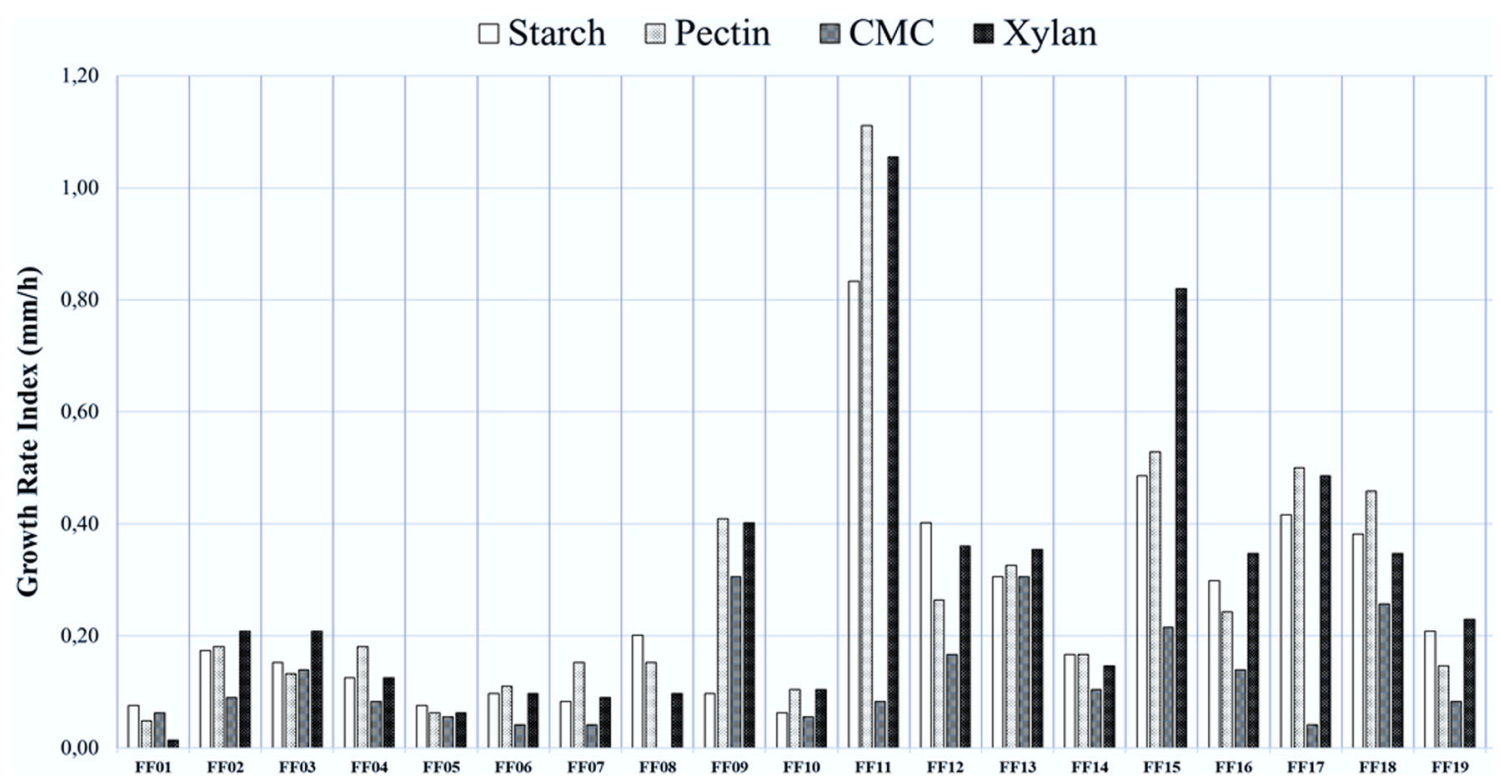

Fig. 2 Growth rate index of filamentous fungi in different carbon sources

class Dothideomycetes; (4) phylum Basidiomycota, class Agaricomycetes.

The following eight (40\%) strains were identified in the Eurotiomycetes cluster: Aspergillus parasiticus FF16, A. versicolor FF05, P. paneum FF04, P. pimiteouiense FF10, P. rubidurum FF06, Talaromyces macrosporus FF02, and T. radicus FF07 (Fig. 3). The following five species were identified in the Sordariomycetes cluster $(n=5,25 \%)$ : Daldinia eschscholtzii FF08, Diaporthe lithocarpus FF18, Diaporthe phaseolorum FF12, Diaporthe pseudomangiferae FF09, and Diaporthe tectonae FF15 (Fig. 4).

The following two species $(n=2,10 \%)$ were identified in the third cluster (Dothideomycetes): Cladosporium cladosporioides FF01 (Fig. 5a) and Phyllosticta capitalensis FF19 (Fig. 5b). Due to the wide diversity of the Dothideomycetes class (Schoch et al. 2009), two reconstructions were carried out to confirm the molecular identifications of FF01 (clade Davidiella) and FF19 (clade Botryosphaeria) (Fig. 5).

In the present study, Ascomycetes accounted for the majority of the fungi isolated, represented by the classes Eurotiomycetes $(8 / 20)$, Sordariomycetes $(5 / 20)$, and Dothideomycetes $(2 / 20)$.

The fourth cluster identified was the class Agaricomycetes (Phylum Basidiomycota), in which Fomitopsis subtropica FF03, Phanerochaete australis FF11, Perenniporia tephropora FF13, Neonothopanus nambi FF14, and Marasmius cladophyllus FF17 were identified (Figs. 4 and 6).

\section{Discussion}

A total of 19 species were identified, of which 16 had not yet been reported during cocoa fermentations in Brazil. This fact evidences the great fungal diversity present in the fermentation process of Amazonian cocoa, showing the importance of studies to identify filamentous fungi in other municipalities of the Brazilian Amazon.

Of the lineages selected, it is known that A. parasiticus is a toxigenic fungus with the potential for aflatoxin production, but it must be remembered that mycotoxin production is influenced by complex interactions between abiotic and biotic factors (water activity, temperature, $\mathrm{pH}$, moisture, and storage time) (Copetti et al. 2011a; Garcia et al. 2011). Researchers have evaluated the occurrence and distribution of aflatoxigenic species as well as the production of aflatoxins during cocoa processing in Bahia (BR), and verified that, despite the high occurrence of aflatoxigenic fungi (A. flavus and A. parasiticus), the levels of aflatoxins found in the samples are low, mainly in the fermentation stage, suggesting that compounds with antitoxigenic properties may be present in cocoa (Adhikari et al. 2015).

Considering the identification of each lineage, a search was made in the literature for papers that associated the presence of these fungi with cocoa fermentation. Research carried out on the microbiota present in cocoa processing in Bahia, Brazil, identified filamentous fungi of the species Aspergillus versicolor, A. parasiticus, and Penicillium paneum (Copetti et al. 2011b), fungi also identified in the present study.

The greater diversity of fungi isolated up to $24 \mathrm{~h}$ of fermentation can be justified by the fact that on the first day of fermentation the cocoa beans presented a large amount of pulp, with no competition for substrate between microorganisms, enabling diversified growth. Another fact that may justify the decrease in the number of filamentous fungi isolated after $48 \mathrm{~h}$ of fermentation, was the increase in temperature observed between the times of 24 $\left(30.72{ }^{\circ} \mathrm{C}\right)$ and $72 \mathrm{~h}\left(40.83{ }^{\circ} \mathrm{C}\right)\left(\Delta \mathrm{T}=10.1^{\circ} \mathrm{C}\right)$. 


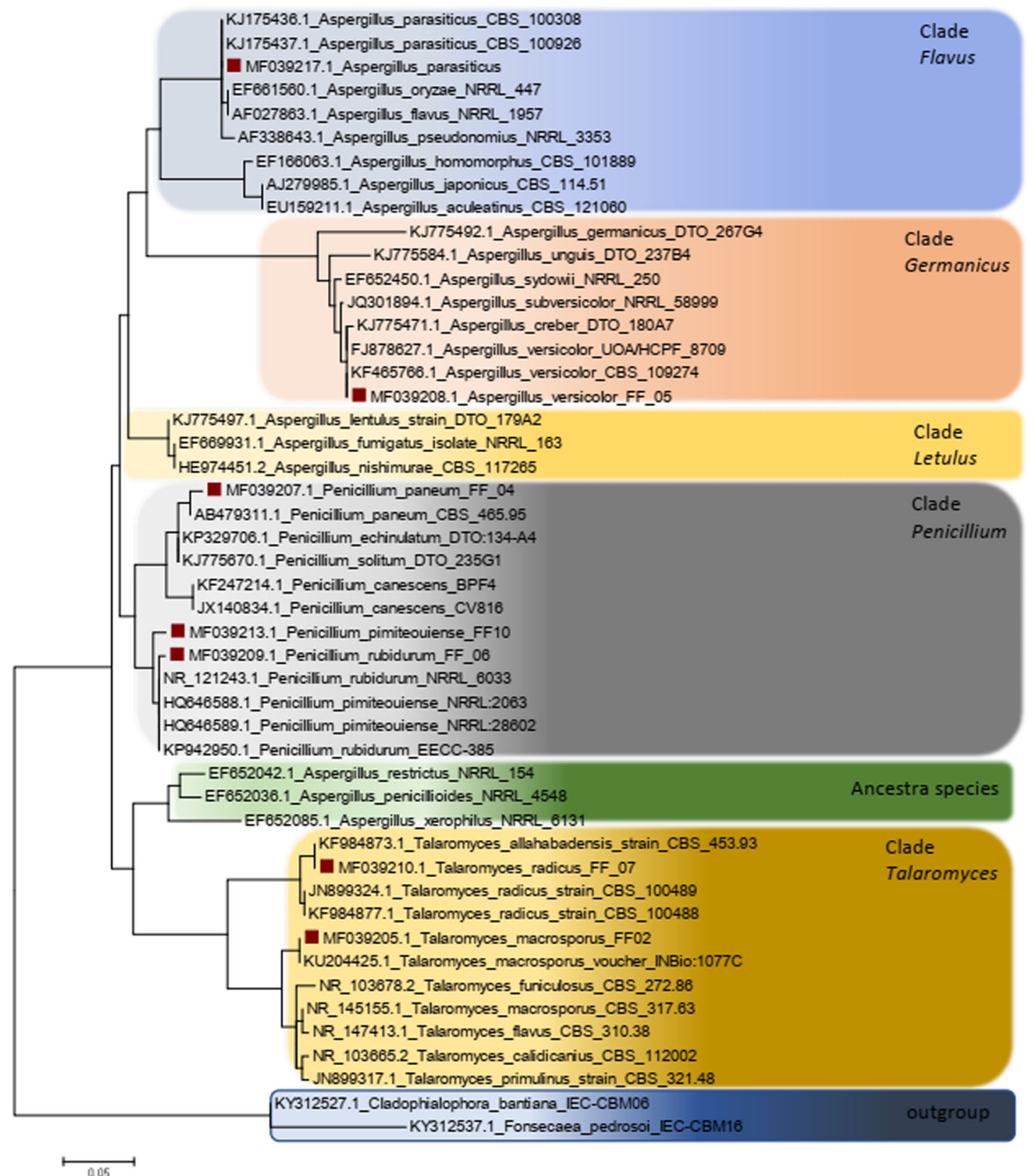

Fig. 3 ITS-based molecular phylogenetic analysis of Eurotiomycetes fungi. The evolutionary history was inferred by using the maximum likelihood method based on the Kimura 2-parameter model (28), 1000 bt replicates, and gamma distribution $(+\mathrm{G})$. Evolutionary analyses were conducted in MEGA7 (REF: MEGA7: Molecular Evolutionary Genetics

With respect to the temperature, the increase is justified by the presence of microorganisms such as yeasts and acetic bacteria that metabolize the fermentable sugars present in the cocoa pulp to ethanol and acetic acid, respectively, in an exothermic way. A study carried out in West Africa showed that the fermentation temperature rose from $29.5^{\circ} \mathrm{C}(0 \mathrm{~h})$ to $39.7^{\circ} \mathrm{C}(144 \mathrm{~h})\left(\Delta \mathrm{T}-10.2{ }^{\circ} \mathrm{C}\right)$ (Stamford et al. 1998). In this context, it is believed that the increase in temperature may inhibit the growth of some species. Thus, temperature control
Analysis version 7.0 for bigger datasets). The tree is drawn to scale, with branch lengths measured in the number of substitutions per site. Bt values are indicated at the node. Clades were named considered ancestral species from this reconstruction. Each sample from this study is marked with a square. Scale 0.05

or temperature monitoring are important points in the evaluation of the profile of filamentous fungi strains.

The reduction in $\mathrm{pH}$ can be related to the lactic and acetic acid bacteria that are usually present in the fermentation process. These bacteria produce organic acids that permeate into the cocoa seeds, thus lowering the $\mathrm{pH}$ value. It is believed that the $\mathrm{pH}$ changes occurring during fermentation do not interfere in fungal growth, since, in general, filamentous fungi can tolerate the low $\mathrm{pH}$ values found in this study. 


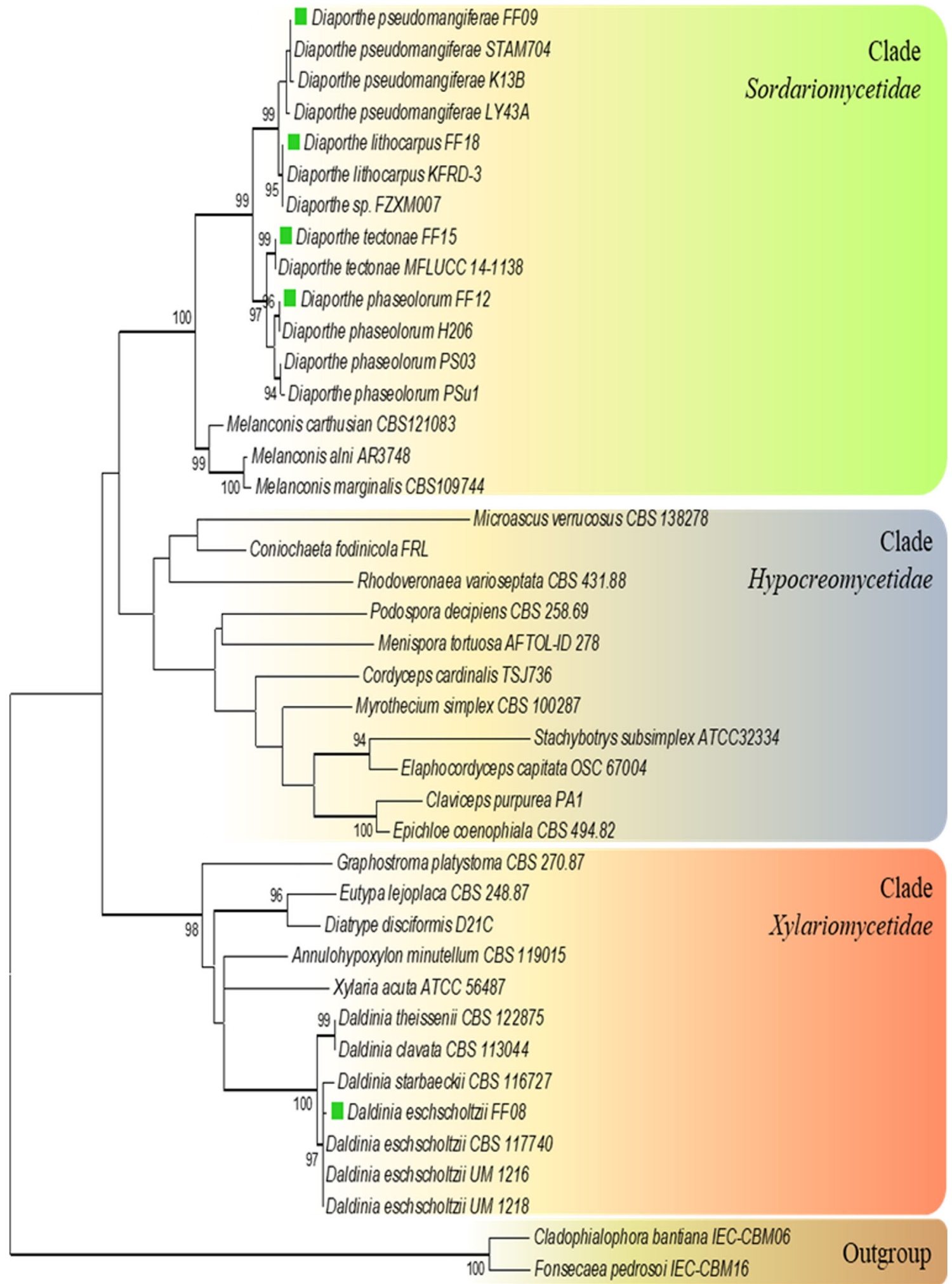

0.05

Fig. 4 ITS-based molecular phylogenetic analysis of Sordariomycetes fungi. Phylogeny was inferred by using the maximum likelihood method based on the Kimura 2-parameter model (28), 1000 bootstrap replicates. It considered gamma distribution $(+G)$ and some sites to be evolutionarily invariable $(+\mathrm{I})$. The percentage of trees in which the associated taxa clustered together is shown next to the branches (bt value). The tree is drawn to scale, with branch lengths measured in the number of substitutions per site. Clades were named considered ancestral species from this reconstruction. Each sample from this study is marked with a square. Scale 0.05 
Fig. 5 ITS-based molecular phylogenetic analysis of Dothideomycetes fungi. a The evolutionary history of clade Davidiella was inferred by using the maximum likelihood method based on the Kimura 2-parameter model (28), gamma distribution $(+\mathrm{G})$, and 1000 bootstrap replicates. b The evolutionary history of clade Botryosphaeria was inferred by using the maximum likelihood method based on the Kimura 2-parameter model [1], gamma distribution $(+\mathrm{G})$ and 1000 bootstrap replicates. The percentage of trees in which the associated taxa clustered together is shown next to the branches. The tree is drawn to scale, with branch lengths measured in the number of substitutions per site. Clades were named considered ancestral species from this reconstruction. Each sample from this study is marked with a square. Scale 0.05
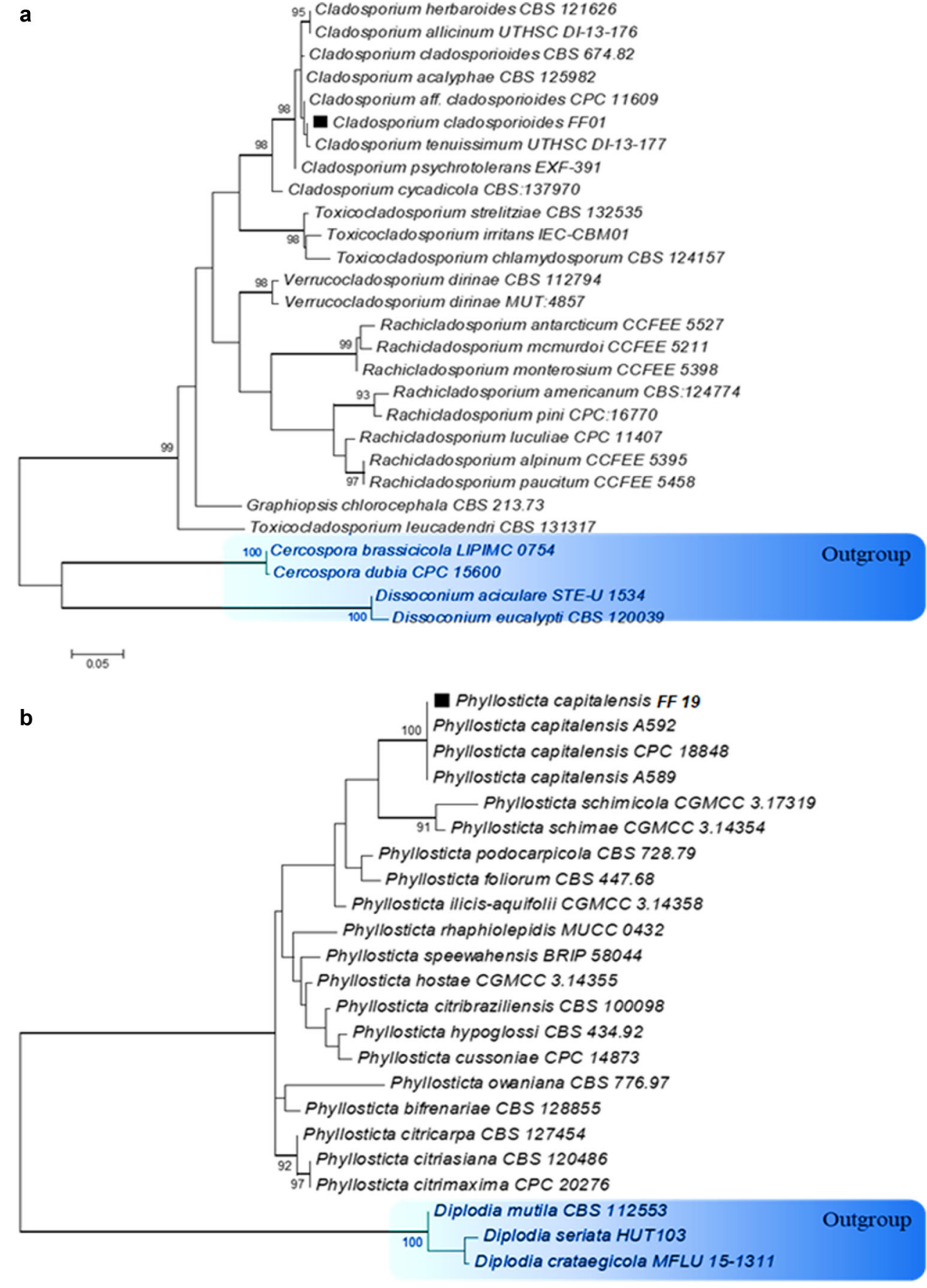

Based on the results of the tests for enzymatic activities, it was observed that most of the strains showed the ability to produce amylases. The role of amylases in the fermentation of cocoa is to provide reducing sugars, which, together with amino acids, will generate the taste of chocolate and precursors of aromatic substances via the Maillard reaction during the roasting phase of the almonds. Thus, it is believed that all the filamentous fungi that showed positive results for the production of amylase are important in the fermentation of cocoa.

The results confirmed the pectinolytic potential of the fungus C. cladosporioides, observed by other authors. However, no reports were found on the pectinolytic potential of F. subtropica and A. versicolor in the fermentation of cocoa seeds, as was observed in the present study. These fungi may 


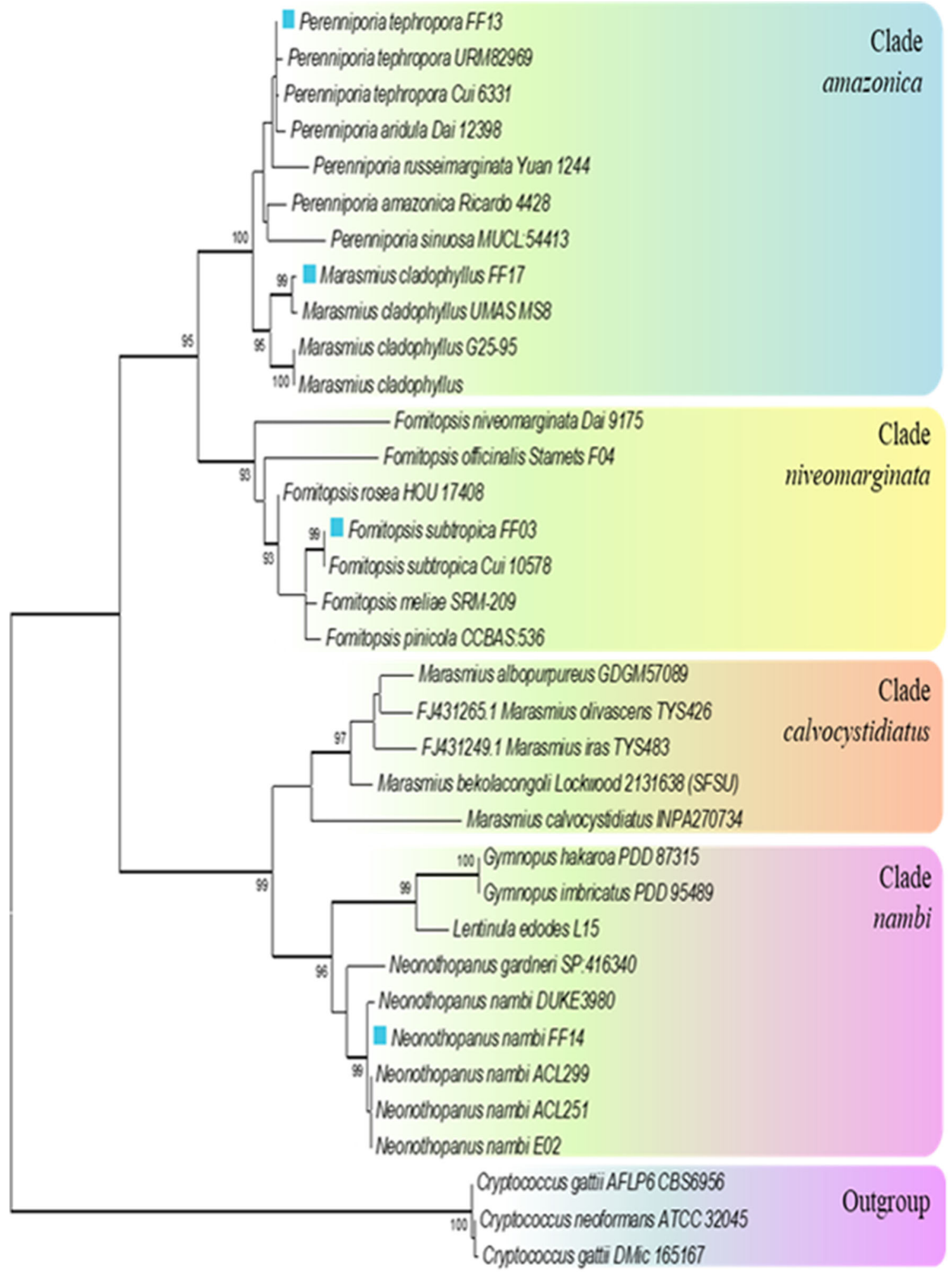

Fig. 6 ITS-based molecular phylogenetic analysis of Agaricomycetes fungi. Phylogeny was reconstructed by using the maximum likelihood method based on the Kimura 2-parameter model (28) and gamma distribution $(+\mathrm{G})$. The bootstrap values of trees in which the associated taxa clustered together are shown next to the branches. Clades were named considered ancestral species from this reconstruction. Each sample from this study is marked with a square. Scale 0.1 
contribute to the fermentation of cocoa since the pectinases provide a greater availability of reducing sugars and improve aeration of the mass through the hydrolysis of the pectin. This process of aeration of the mass contributes to the growth of aerobic microorganisms that also act in the fermentation.

Several studies have demonstrated the cellulolytic activity of $A$. versicolor and $F$. subtropical but no scientific reports for P. pimiteouiense were found. The best EI value (4.0) was found for $C$. cladosporioides. Thus, these fungi, when present in cocoa fermentations, may contribute beneficially, since the pulp presents an amount of cellulose that needs to be hydrolyzed to produce glucose molecules, that can be consumed by other microorganisms present in the fermentation or participate in the Maillard reaction.

No correlation was found in the literature concerning the production of xylanases by the fungus $N$. nambi. However, there are several studies that demonstrate the xylanolytic activity of A. versicolor and C. cladosporioides. A study carried out with $C$. cladosporioides found that this fungus exhibits great potential for the rapid secretion of xylanases (Hong et al. 2011).

The good results obtained for the enzymatic activities of the fungus $P$. australis with two carbon sources (pectin and xylan) show the adaptation of this microorganism to different carbon sources. In this context, it was assumed that this filamentous fungus was a good producer of pectinase and xylanase, since it presented high GRI values in the tests. This possibly justifies the absence of halos or low EI values, since the growth may be parallel to secretion of the enzyme. This may demonstrate that this fungus has the capacity to produce/secrete enzymes from different substrates in a short time, and therefore, its presence during cocoa fermentation may be favorable, since some studies aim to reduce the fermentation time.

Correlating the GRI with the EI, it was observed that the isolates that obtained good EI values showed relatively low GRI values, a fact that may be related to the initial energy expenditure required for the production and secretion of enzymes, or simply because it is a physiological characteristic of these fungi. This fact demonstrates the importance of using more than one test to evaluate the enzymatic potential of fungi when using several species, since each species has peculiar metabolic characteristics which makes it difficult to observe the enzymatic potential in just one test.

The enzymatic potential of six strains (C. cladosporioides, F. subtropica, A. versicolor, P. pimiteouiense, N. nambi, and A. parasiticus) was detected. However, a more diversified enzymatic activity was observed in $C$. cladosporioides. It is important to note that there are no data available to correlate the presence of this fungus with good quality cocoa fermentation. However, in the processing of coffee, fungi of the genus Cladosporium have been associated with quality coffee, since they rapidly consume the mucilage of the fruit, preventing the development of other microorganisms that can produce undesirable substances (Oliveira et al. 2011).
Most of the fungi identified in this study had not previously been found in cocoa fermentations, but some have a normal distribution and are mainly isolated from the soil, as is the case for some species of the genus Talaromyces (Lundell et al. 2010) and Fomitopsis (Lucheta et al. 2016). This fact possibly justifies the presence of the species found, since, after harvesting, the cocoa fruits come into contact with the soil when they are left for $24 / 48 \mathrm{~h}$ to rest before the fruit is broken for later fermentation.

Metagenomic analysis during cocoa fermentation has demonstrated a diversity of cultivable and non-cultivable microorganisms in the core and subcore groups. In a more recent review article, a prevalence of the genus Aspergillus was demonstrated within the group of filamentous fungi (Ozturk and Young 2017), which was not observed in this study. However, as already mentioned, we have identified other species not yet reported. It was observed in the present study that ascomycetes represented the majority of the strains isolated (three of the four clusters). This was also observed in environmental studies on the composition of fungal microorganisms in Brazilian biomes (Mcguire et al. 2012; Peay et al. 2013).

The fourth cluster identified was the class Agaricomycetes (phylum Basidiomycota). This class also includes species of economical, clinical, and biotechnological interests. Agaricomycetes are known to play an important role in the decomposition of organic matter in an environment of enriched vegetable matter (Mcguire et al. 2012).

Many studies have correlated the presence of filamentous fungi with the production of mycotoxins during the fermentation and drying of cocoa beans, but studies that associate these microorganisms with quality fermentation are rare. To date, it is not known whether filamentous fungi contribute effectively to the fermentation of cocoa beans. However, in the present study, it was verified that some species of filamentous fungi could contribute positively to the fermentation, since they have the capacity to secrete hydrolytic enzymes that are important for the fermentation process, besides having applications in biotechnological industries.

\section{Conclusion}

Of the 19 species found, 16 had not yet been reported in cocoa fermentation in Brazil or in other countries. This fact is evidence that the Amazon cocoa has a wide diversity of filamentous fungi such as Cladosporium cladosporioides, Fomitopsis subtropica, Aspergillus versicolor, Penicillium pimiteouiense, Phanerochaete australis, Neonothopanus nambi, and Aspergillus parasiticus, which have a high potential for the secretion of hydrolytic enzymes of biotechnological interest. The understanding of the participation of filamentous fungi in the fermentation of cocoa still needs further studies, but the 
authors believe that the present study will start such an understanding in order to obtain products with better quality, especially in the Amazon region, that has an important role in the production of cocoa seeds.

Acknowledgments The authors wish to thank the Evandro Chagas Institute (IEC/SVS/MS) for the PCR analyses, and the Graduate Program in Food Science and Technology of the Federal University of Pará (PPGCTA/UFPA) for providing the infrastructure. GO is funded by CNPq (307479/2016-1) and the Global Challenges Research Fund, UK Research and Innovation (BB/P027849/1 - CABANA).

Funding This work was supported by the Instituto Tecnologico Vale (Cacau P2) (Brazil) and the Conselho Nacional de Desenvolvimento Cientifico e Tecnológico $(\mathrm{CNP} q)$.

\section{Compliance with ethical standards}

Conflict of interest The authors declare they have no conflicts of interest.

Research involving human participants and/or animals Not applicable.

Informed consent Not applicable.

\section{References}

Abdullahi G, Muhamad R, Dzalkhifli SUR, Sinniah UR (2018) Analysis of quality retentions in cocoa beans exposed to solar heat treatment in cardboard solar heater box. Cogent Food Agric 4: 1483061. https://doi.org/10.1080/23311932.2018.1483061

Adhikari M, Yadav DR, Kim S, Um YH, Kim HS, Lee HB, Lee YS (2015) Discovery of two new Talaromyces species from crop field soil in Korea. Mycobiology 43(4):402-407. https://doi.org/10.5941/ MYCO.2015.43.4.

Alvarez-Navarrete M, López GR, García AF, López GR, MartínezPacheco MM (2015) Selection and molecular identification of fungal isolates that produce xylanolytic enzymes. Genet Mol Res 14: 8100-8116. https://doi.org/10.4238/2015.July.17.19

Downes FP, Ito K (2001) Compendium of methods for microbiological examination of foods, 4th ed. American Public Health Association (APHA), Washington, D. C.

Bouras N, Kim YM, Strelkov SE (2009) Influence of water activity and temperature on growth and mycotoxin production by isolates of Pyrenophora tritici-repentis from wheat. Int J Food Microbiol 131:251-255. https://doi.org/10.1016/j.ijfoodmicro.2009.02.001

Chan LG, Cohen JL, Bell JMLNM (2018) Conversion of agricultural streams and food-processing by-products to value-added compounds using filamentous fungi. Annu Rev Food Sci T 9:503523. https://doi.org/10.1146/annurev-food-030117-012626

Chen YC, Eisner JD, Kattar MM, Rassoulian-Barrett SL, Lafe K, Bui U, Limaye AP, Cookson BT (2001) Polymorphic internal transcribed spacer region 1 DNA sequences identify medically important yeasts. J Clin Microbiol 39:4042-4051. https://doi.org/10.1128/JCM.39. 11.4042-4051.2001

Cocolin L, Ercolini D (2008) Molecular techniques in the microbial ecology of fermented foods. Springer, New York

Copetti MV, Iamanaka BT, Pereira JL, Frisvad JC, Taniwaki MH (2011a) Mycobiota of cocoa: from farm to chocolate. Food Microbiol 28: 1499-1504. https://doi.org/10.1016/j.fm.2011.08.005
Copetti MV, Iamanaka BT, Pereira JL, Fungaro MH, Taniwaki MH (2011b) Aflatoxigenic fungi and aflatoxin in cocoa. Int J Food Microbiol 148(2):141-144. https://doi.org/10.1016/j.ijfoodmicro. 2011.05.020

Damaso MCT, Terzi SC, Farias AX, Oliveira ACP, Fraga ME, Couri S (2012) Selection of cellulolytic fungi isolated from diverse substrates. Braz Arch Biol Techn 55(4):513-520. https://doi.org/10. 1590/S1516-89132012000400005

Deb P, Talukdar SA, Mohsina K, Sarker PK, Sayem SMA (2013) Production and partial characterization of extracellular amylase enzyme from Bacillus amyloliquefaciens P-001. Springerplus. https:// doi.org/10.1186/2193-1801-2-154

Dias MD, Pozza EA, Abreu MS, Miranda EO (2005) Effect of temperature on mycelial growth, production and conidial germination of Colletotrichum spp from Coffea arabica L. Cienc Agrotec 29(3):545552

Felsenstein J (1985) Confidence limits on phylogenies: an approach using the bootstrap. Evolution 39:783-791. https://doi.org/10.1111/j. 1558-5646.1985.tb00420.x

Garcia D, Ramos AJ, Sanchis V, Marín S (2011) Modelling the effect of temperature and water activity in the growth boundaries of Aspergillus ochraceus and Aspergillus parasiticus. Food Microbiol 28(3):406-417. https://doi.org/10.1016/j.fm.2010.10.004

Godet M, Munaut F (2010) Molecular strategy for identification in Aspergillus section Flavi. FEMS Microbiol Lett 304(2):157-168. https://doi.org/10.1111/j.1574-6968.2009.01890.x

Hankin L, Anagnostakis SL (1975) The use of solid media for detection of enzymes production by fungi. Mycologia 67(3):597-607

Hong JY, Kim YH, Jung MH, Jo CW, Choi JE (2011) Characterization of xylanase of Cladosporium cladosporioides $\mathrm{H} 1$ isolated from Janggyeong Panjeon in Haeinsa Temple. Mycobiology :306-309. https:// doi.org/https://doi.org/10.5941/MYCO.2011.39.4.306

Justé A, Thommad BPHJ, Lievens B (2008) Recent advances in molecular techniques to study microbial communities in food-associated matrices and processes. Food Microbial 25:745-761. https://doi.org/ 10.1016/j.fm.2008.04.009

Khokhar IB, Mukhtar I, Mushtaq S (2011) Isolation and screening of amylolytic filamentous fungi. J Appl Sci Environ Manage 15(1): 203-206. https://doi.org/10.4314/jasem.v15i1.68442

Kumar S, Stecher G, Tamura K (2016) Mega7: molecular evolutionary genetics analysis version 7.0 for bigger datasets. Mol Biol Evol 33(7):1870-1874. https://doi.org/10.1093/molbev/msw054

Larone DH (2002) Medically important fungi - A guide to identification, 4rd edn. American Society for Microbiology Press, Washington

Lucheta AR, Cannavan FS, Roesch LFW, Tsai SM, Kuramae EE (2016) Fungal community assembly in the Amazonian dark earth. Microb Ecol 71(4):962-973. https://doi.org/10.1007/s00248-015-0703-7

Lundell TK, Mäkelä MR, Hildén K (2010) Lignin-modifying enzymes in filamentous basidiomycetes - ecological, functional and phylogenetic review. J Basic Microb 50:5-20. https://doi.org/10.1002/ jobm. 200900338

Macedo ASL, Negreiros CVB, Bispo ES, Silva AS, Druzian JI (2013) A prospective study of cocoa fermentation (Theobroma cacao L.) under the focus on patent applications filed in the world between 1899 and 2012. GEINTEC-Gestão, Inovação e Tecnologias 3(5):362-371 (in Portuguese. https://doi.org/10.7198/S2237-0722201300050029

Mcguire KL, Fierer N, Bateman C, Treseder KK, Turner BL (2012) Fungal community composition in neotropical rain forests: the influence of tree diversity and precipitation. Microb Ecol 63:804-812. https://doi.org/10.1007/s00248-011-9973-x

Mounjouenpou P, Gueule D, Guyot B, Tondje PR, Fontana-Tachon A, Guiraud JP (2012) Incidence of pod integrity on the fungal microflora and ochratoxin-a production in cocoa. JBLS 3(1):254-265. https://doi.org/10.5296/jbls.v3i1.2231

Najafzadeh MJ, Sun J, Vicente V, Xi L, Hoog GS (2010) Fonsecaea nubica $\mathrm{sp}$. a new species of agent of human chromoblastomycosis 
revealed using molecular data. Med Mycol 48(6):800-806. https:// doi.org/10.3109/13693780903503081

Nielsen DS, Teniola OD, Ban-Koffi L, Owusu M, Andersson TS, Holzapfel WH (2007) The microbiology of Ghanaian cocoa fermentation analyzed using culture-dependente and culture-independent methods. Int J Food Microbiol 114(2):168-186. https://doi.org/10. 1016/j.jfoodmicro.2006.09.010

Oliveira TO, Pimenta CJ, Cardoso PG, Souza SMC, Fabrício LFF, Leal RS (2011) Production of pectin lyase by isolates Cladosporium cladosporioides using submerged fermentation and grape skin as substrate. Higiene Alimentar 25:217-218

Ozturk G, Young GM (2017) Food evolution: the impact of society and science on the fermentation of cocoa beans. CRFSFS 16:431-455. https://doi.org/10.1111/1541-4337.12264

Peay KG, Baraloto C, Fine PVA (2013) Strong coupling of plant and fungal community structure across western Amazonian rainforests. The ISME J 7:1852-1861. https://doi.org/10.1038/ismej.2013.66

Reddy PL, Sreeramulu A (2012) Isolation, identification and screening of pectinolytic fungi from different soil samples of Chittoor district. Int J Life Sci Biotechnol Pharma Res 1(3):186-193

Schoch CL, Crous PW, Groenewald JZ, Boehm EWA, Burgess TI, De Gruyter J et al (2009) A class-wide phylogenetic assessment of Dothideomycetes. Stud Mycol 64:1-15. 10.3114\%2Fsim.2009.64.01

Schoch CL, Crous PW, Groenewald JZ, Boehm EWA, Burgess TI, Gruyter J de, Hoog GS de, Dixon LJ, Grube M, Gueidan C, Harada Y, Hatakeyama S, Hirayama K, Hosoya KT, Huhndorf SM, Hyde KD, Jones EBG, Kohlmeyer J, Kruys Å, Li YM, Lücking R, Lumbsch HT, Marvanová L, Mbatchou JS, McVay AH, Miller AN, Mugambi GK, Muggia L, Nelsen MP, Nelson P, Owensby CA, Phillips AJL, Phongpaichit S, Pointing SB, PujadeRenaud V, Raja HA, Rivas Plata E, Robbertse B, Ruibal C, Sakayaroj J, Sano T, Selbmann L, Shearer CA, Shirouzu T, Slippers B, Suetrong S, Tanaka K, Volkmann-Kohlmeyer B, Wingfield MJ, Wood AR, Woudenberg JHC, Yonezawa H, Zhang Y, SpataforaCrous JW, Groenewald JZ, Boehm EWA, Burgess TI,
Gruyter J de, Hoog DS de, Dixon LJ, Grube M, Gueidan C, Harada Y, Hatakeyama S, Hirayama K, Hosoya T, Huhndorf SM, Hyde KD, Jones EBG, Kohlmeyer J, Kruys Å, Li YM, Lücking R, Lumbsch HT, Marvanová L, Mbatchou JS, McVay AH, Miller AN, Mugambi GK, Muggia L, Nelsen MP, Nelson P, Owensby CA, Phillips AJL, Phongpaichit S, Pointing SB, Pujade-Renaud V, Raja HA, Rivas Plata E, Robbertse B, Ruibal C, Sakayaroj J, Sano T, Selbmann L, Shearer CA, Shirouzu T, Slippers B, Suetrong S, Tanaka K, Volkmann-Kohlmeyer B, Wingfield MJ, Wood AR, Woudenberg JHC, Yonezawa H, Zhang Y, Spatafora JW (2009) A class-wide phylogenetic assessment of Dothideomycetes. Stud Mycol 64:115. https://doi.org/10.3114/sim.2009.64.01

Stamford TLM, Araújo JM, Stamford NP (1998) Enzymatic activity of microorganisms isolated from yam bean legume (Pachyrhizus erosus L. Urban). Food Sci Tech-Brazil 18(4):382-385. https://doi. org/10.1590/S0101-20611998000400004

Teather RM, Wood PJ (1982) Use of Congo red-polysaccharide interactions in enumeration and characterization of cellulolytic bacteria from the bovine rumen. Appl Environ Microb 43:777-780

Visintin S, Alessandria V, Valente A, Dolci P, Cocolin L (2016) Molecular identification and physiological characterization of yeasts, lactic acid bacteria and acetic acid bacteria isolated from heap and box cocoa bean fermentations in West Africa. Int J Food Microbiol 216:69-78. https://doi.org/10.1016/j.ijfoodmicro.2015.09.004

Watanabe T (2010) Pictorial atlas of soil and seed fungi - morphologies of cultured fungi and key to species. CRC Press, New York

Publisher's note Springer Nature remains neutral with regard to jurisdictional claims in published maps and institutional affiliations. 